\title{
Effects of Namya Kanom Jeen powder extract on hypoglycemic and antioxidant properties in Alloxan-induced diabetic rats
}

\author{
Preeya Dat-arun $^{1}$, Rattana Leelawattana $^{2}$, and Pavinee Chinachoti ${ }^{1}$ \\ ${ }^{1}$ Interdisciplinary Graduate School of Nutraceutical and Functional Food, Learning Resource \\ Center, Prince of Songkla University, Hat-Yai, Songkhla, 90110, Thailand; ${ }^{2}$ Division of \\ Endocrinology and Metabolism, Department of Medicine, Faculty of Medicine, Prince of \\ Songkla University, Hat- Yai, Songkhla, 90110, Thailand
}

Corresponding author: Professor Dr. Pavinee Chinachoti, Interdisciplinary Graduate School of Nutraceutical and Functional Food, Learning Resource Center, Prince of Songkla University, Hat-Yai, Songkhla, 90110, Thailand

Submission date: August $23^{\text {rd }}, 2018$, Acceptance Date: December $28^{\text {th }}, 2018$, Publication Date: December $30^{\text {th }}, 2018$

Citation: Dat-arun P., Leelawattana R., Chinachoti P. Effects of Namya Kanom Jeen powder extract on hypoglycemic and antioxidant properties in Alloxan-induced diabetic rats. Bioactive Compounds in Health and Disease 2018; 1(12): 86-100. DOI: https://doi.org/10.31989/bchd.v1i8.549

\begin{abstract}
Background: Diabetes mellitus (DM) is a major health care problem worldwide. Major intervention control of DM involves medical treatments and dietetic therapy. Spices and herbs have been known to have anti-oxidant, anti-inflammation, and anti-diabetic properties. Southern Thai foods contain large amounts of phytochemicals and have been demonstrated to exhibit these properties. In particular, Namya Kanom Jeen (NKJ), a Southern Thai soup, was the most promising. In this study, we studied the effect of NKJ water extracts on hypoglycemic and antioxidant properties in Alloxan-induced diabetic rats.
\end{abstract}

Methods: This study aimed to assess the effect of $N K J$ water extract on blood glucose, insulin, malondialdehyde (MDA), homeostatic model assessment of insulin resistance (HOMA-IR), and high sensitive C-reactive protein (hs-CRP) levels in Alloxan-induced diabetic (DM) rats for 3 weeks.

Results: In Alloxan-induced diabetic rats, the $N K J$ water soluble extracts at 200, 1000, and $2000 \mathrm{mg} / \mathrm{kg}$ body weight doses $(\mathrm{n}=7)$ significantly lowered blood glucose, insulin, MDA, and HOMA-IR levels compared to diabetic control (Metformin, $\mathrm{p}<0.05$ ).

Conclusion: In conclusion, consumption of $N K J$ aqueous extract effectively lowered baseline blood glucose, insulin, MDA, and HOMA-IR in diabetic rats. 
Keywords: Diabetes mellitus; Anti-oxidant; Glycemic; Insulin resistance; HOMA-IR, Namya Kanom Jeen powder

\section{INTRODUCTION}

Globally, the prevalence of diabetes is increasing at an alarming rate. The numbers of diabetic patients may more than double within fifteen years [1]. Diabetes mellitus (DM) is a chronic metabolic syndrome disease resulting from a dysfunction of pancreatic $\beta$-cells that fail to secrete insulin after ingestion of carbohydrates, resulting in high blood glucose [2]. Oxidativestress induced inflammation may play an important role in developing DM [3, 4].

Hyperglycemia induces oxidative stress forming reactive oxygen species (ROS) and accumulation of free radicals reported to trigger diabetic complication [5]. Hyperglycemiainduced overload of superoxide radicals leads to an excess of cellular reactive oxygen and nitrogen species (ROS and RNS respectively) [6, 7], promotion of non-enzymatic glycoxidation of proteins and lipids [8], and an increase in sorbitol and fructose formed through polyol pathway [9]. Moreover, excess superoxide radical production in mitochondrial respiratory chains also activate necrosis factor (i.e. kappa $\mathrm{B}(\mathrm{NF}-\kappa \mathrm{B})$ ), which leads to the production of nitric oxide (NO) induced by inducible Nitric Oxide Synthase (iNOS) enzymes [10]. NO combines with superoxide anions to produce peroxynitrite anions which are capable of oxidizing biomolecules, such as protein, lipid, amino acids, and DNA, resulting in cell injury and deaths [11].

The main approach to the treatment of DM is drugs with anti-diabetic activities, coupled with insulin treatment, appropriate diet, and exercise [12]. However, most DM medication treatments have side effects. Furthermore, prolonged use may lead to diminished response [13]. In contrast, natural compounds like polyphenols in plant-based foods have gained considerable attention as of late for being an attenuated factor of the diabetic condition [14]. The polyphenols may influence glucose metabolism via several mechanisms, including glucose absorption in the intestine, stimulation of insulin secretion from pancreatic $\beta$-cells, modulation of glucose release from the liver, activation of insulin receptors and glucose uptake in the insulin-sensitive tissues, and modulation of hepatic glucose output [15].

Recently, various intact herbs and spices have been used successfully to manage type 2 diabetes, most prominently with cases for DM [16]. Despite such potentially beneficial effects of spices and herbs, interpreting the actions of their bioactive compounds is complicated [17]. Each spice contains a wide range of bioactive compounds. Thus, combining bioactive compounds may lead to a synergistic effect [18]. Moreover, the daily intake of individual spices is uncommon. Therefore, a better understanding of the anti-diabetic potential effect on whole foods as the traditional way it is consumed dish in the prevention of diabetes, with associated complications and metabolic abnormalities.

Southern Thai food contains a large number of phytochemicals having herbs, spices, diverted fruit, and vegetable varieties. If selected carefully, these foods have potentially high health functional values. The selection of food products has increased interest, particularly for the consumption of plant-based foods which have health promoting benefits. Phytochemicals in plant foods are bioactive compounds, such as natural antioxidants, several of which exhibit health-promoting effects against certain chronic diseases such as diabetes, obesity, cardiovascular disease, and cancer [19]. The positive effects of some specific Thai foods in in vitro and in vivo models have been reported. Stir-fried chicken with green curry can suppress inflammatory gene expression by lipopolysaccharide -induced murine macrophages [20]. Thai Red Curry Paste (TRCP) extracts can decrease baseline blood glucose, liver enzyme activities, 
hyperinsulinemia, and serum MDA and ROS in diabetic rats [21]. The great challenge is to find probable effects of indigenous food(s) that could potentially relieve the pathogenesis of metabolic syndrome diseases.

Based on our earlier screening of twelve Southern Thai foods, NKJ (Namya Kanom Jeen water extract) ranked higher in vitro in biological properties and found that the water extract of $N K J$ demonstrated the highest antioxidant activity by DPPH radical scavenging properties [22].

Accordingly, we decided to continue an in vivo study with $N K J$ extract. The objective was to evaluate the the reduction of baseline glucose, insulin response, and other biomarkers of diabetic responses in Alloxan-induced diabetic rats. The effects of $N K J$ powder extract are compared with the hypoglycemic Metformin ( $200 \mathrm{mg} / \mathrm{kg}$ body weight) as reference compound.

\section{MATERIALS AND METHODS}

\section{Chemicals and reagents}

Alloxan monohydrate were purchased from Sigma-Aldrich Corporation (St. Louis, Missouri, USA).

\section{Sample preparation: Namya Kanom Jeen (NKJ)}

Namya Kanom Jeen (NKJ) consisting of 34.2\% (w/w) of boiled and deboned fish, $1.0 \%$ dry hot chili (Capsicum frutescens Linn.), 1.4\% garlic (Allium sativum Linn.), 0.2\% turmeric (Curcuma Longa Linn), 1.0\% lemongrass (Cymbopogon citratus Stapf), 0.5\% pepper (Piper nigrum Linn.), 1.5\% shallot (Allium ascalonicum Linn.), 0.7\% fermented shrimp paste, $68.2 \%$ coconut milk, $0.34 \%$ garcinia (Garcinia Cambogia), $0.21 \%$ salt, and $0.7 \%$ kaffir lime (Citrus hystrix DC.) leaves.

All ingredients were obtained from the Plaza Market at Hatyai, Songkhla Province in 3 batches. The cooking method was prepared traditionally in a Thai kitchen following, modified by Charoenkiatkul and co-workers [23]. The coconut milk was heated to a boil, followed by the addition of ground fish mixed with the curry paste, stirred and cooked at temperature 75$90^{\circ} \mathrm{C}$ for $40 \mathrm{~min}$. Salt and garcinia were added to the mixture and then topped with kaffir lime leaves.

Five hundred grams of the finished $N K J$ was blended (Panasonic Blender MX 151 SP, $\mathrm{J}$ a p a $)$ and freeze-dried $\left(0.055 \mathrm{mbar}, 12 \mathrm{~h}\right.$, at $-40^{\circ} \mathrm{C}$, Dura Dry, Dura Freeze Dryer, Canada). Dried samples (moisture content $2.25 \pm 0.02 \%$ ) were milled to fine (20 mesh sieve) powders (3 $\mathrm{s}$, Super Blender, AIKO, China) and stored in plastic bottles with screw caps at $-20^{\circ} \mathrm{C}$ until extraction and proximate analyses.

\section{Proximate analyses of freeze dried samples}

Proximate analyses included moisture, ash, protein, fat and crude fiber contents [24]. Mineral contents (including iron, zinc, sodium, calcium, magnesium, potassium, and phosphorus) were determined by modified AOAC 990.08 [24] by using digestion of wet samples with nitric acid followed by Inductively Coupled Plasma Atomic Emission Spectrometric measurement (ICPAES, Perkin Elmer, USA).

\section{Preparation of foods extracts}

Freeze-dried $N K J$ samples were first extracted with hexane at $1: 10(\mathrm{w} / \mathrm{v}$ powder/hexane) ratio before mixing for 30s (Vortex-mixer Genie 2 G560E, Scientific Industries, USA) and sonicated for $15 \mathrm{~min}$ (Digital Ultrasonic Cleaner 4820, Blazer, USA). After centrifugation $(2,432 \times g$, 
Hettich Zentrifugen, MIKRO 22R, Buckinghamshire, U.K.), pellets were extracted with hexane again to 2 more times. After being left to dry at $30^{\circ} \mathrm{C}$ (ambient air) for $30 \mathrm{~min}$, the pellet sample was extracted with water at dried pellet: water ratio of 1:30 (w/v). After being shaken for $1 \mathrm{~h}$ ambient at $120 \mathrm{rpm}$ (WiseShake ${ }^{\circledR}$, SHO-2D, Wertheim, Germany), aliquot was centrifuged at $2432 \times g$ for $15 \mathrm{~min}$ at $4^{\circ} \mathrm{C}$. The supernatant fractions were evaporated under vacuum $\left(175 \mathrm{mmHg}, 45-50^{\circ} \mathrm{C}\right)$ for $30 \mathrm{~min}$ before freeze-dried (same condition as above) and stored in brown bottles at $-20^{\circ} \mathrm{C}$ until analyzed.

\section{Diabetic or DM Animal models}

A total of 49 male Wistar rat 3 months of ages (weight 270-320 g) were bred and maintained on rodent chow from an animal house facility, Faculty of Science, Prince of Songkla University. Three rats were placed in a stainless-steel wire-mesh cage in a climate-controlled room. The room was controlled for 12-hour, light-dark cycle and a temperature between 23$25^{\circ} \mathrm{C}$. Before commencement of the experiment, the rats could acclimate at the animal house for one week. All animals were maintained following the Animal Care Ethical Committee regulation of Prince of Songkla University, Thailand.

\section{Induction of Diabetes mellitus}

Diabetes was induced by intraperitoneally administering Alloxan monohydrate (SigmaAldrich, Switzerland) at $100 \mathrm{mg} / \mathrm{kg}$ body weight). Alloxan was prepared by dissolving in $0.9 \%$ $\mathrm{NaCl}$ injectable solution to make $50 \mathrm{mg}$ Alloxan $/ \mathrm{ml}$. Alloxan was injected at a dose of $50 \mathrm{mg} / \mathrm{kg}$ to overnight-fasting rats intraperitoneally for three consecutive days to induce DM [25]. Seven days after Alloxan injection [26], fasting blood glucose levels collected from the tail vein of all animals were determined using a portable glucose meter (Accu-Check Performa, Roche Diagnostics Ltd, Germany). Animals with blood glucose levels higher than $200 \mathrm{mg} / \mathrm{dl}$ were chosen for diabetic group. Metformin $(200 \mathrm{mg} / \mathrm{kg})$ was used as the positive control reference. The animals were divided into seven groups:

Group 1: Non-diabetic rats served as hs-CRP baseline in healthy rats $(\mathrm{N}=7)$.

Group 2: Diabetic rats served as hs-CRP baseline in DM rats $(\mathrm{N}=7)$.

Group 3: Diabetic rats treated with saline solution served as diabetes control group $(\mathrm{N}=7)$.

Group 4: Diabetic rats treated with Metformin $200 \mathrm{mg} / \mathrm{kg}$ body weight serving as a control reference $(\mathrm{N}=7)$

Group 5: Diabetic rats treated with aqueous extract of $N K J$ at $200 \mathrm{mg} / \mathrm{kg}$ body weight $(\mathrm{N}=7)$. Group 6: Diabetic rats treated with aqueous extract of $N K J$ at $1,000 \mathrm{mg} / \mathrm{kg}$ body weight $(\mathrm{N}=7)$ Group 7: Diabetic rats treated with aqueous extract of $N K J$ at $2,000 \mathrm{mg} / \mathrm{kg}$ body weight $(\mathrm{N}=7)$

All animals were allowed unlimited access to tap water, pellet diet, and maintained at room temperature in stainless cages throughout the experimental protocol. For the baseline data, the animal model in groups 1, 2, and 3 fasted overnight and blood samples were collected by cardiac puncture under thiopental anesthesia $(50 \mathrm{mg} / \mathrm{kg})$.

Food extract powder (amount $2.5 \mathrm{~g}$ ) was suspended in $5 \mathrm{ml}$ of distilled water (concentration $500 \mathrm{mg} / \mathrm{ml}$ ) and was fed to the group 5, 6, and 7 rats by gastric intubation using a force-feeding needle for 21 days. During this experiment, the amount of food intake was monitored daily. Body weight and blood glucose were measured weekly. Fasting blood samples were collected from the tail vein for the measurement of blood glucose. The amount of dry crude extract was equivalent to 1,5 , and 10 servings/day (200 $\mathrm{ml}$ in wet weight/serving size) of $N K J$ consumed in a normal diet. 


\section{Biochemical analyses}

At the end of the experiment, all animals were fasted overnight, and $5 \mathrm{ml}$ of blood samples was collected from cardiac puncture under thiopental anesthesia $(50 \mathrm{mg} / \mathrm{kg})$ in anti-coagulate tube. Then, plasma samples were prepared by centrifuging the bloods samples at $1096 \square \mathrm{g}$ for 15 min and immediately frozen at $-20^{\circ} \mathrm{C}$ until analyze. Blood glucose concentration was monitored by glucose oxidase-peroxidase method [27]. Plasma insulin concentration was measured using a rat insulin ELIZA kit (KA3811, Abnova, USA) with a detection limit less than $5 \mu \mathrm{IU} / \mathrm{ml}$. Plasma CRP concentration was measured using Cardiac C-Reactive Protein High Sensitive (Roche Diagnostics, Mannheim, Germany) with a detection limit of $0.15 \mathrm{mg} / \mathrm{l}$ and an extended measuring range of $0.15-20 \mathrm{mg} / 1$.

\section{Determination of malondialdehyde (MDA)}

MDA was used as a measure of lipid peroxidation [28]. Briefly, $20 \mu 1$ of plasma were mixed with $500 \mu \mathrm{l}$ of $42 \mathrm{mM} \mathrm{H}_{2} \mathrm{SO}_{4}$ then added with $125 \mu \mathrm{l}$ of $10 \%$ Trichroloacetic acid and placed at room temperature for $5 \mathrm{~min}$. Afterwards, samples were centrifuged at $13000 \mathrm{~g}$ for $5 \mathrm{~min}$. Pellet of samples were kept and re-suspended with $198 \mu \mathrm{l}$ of DI contained Butylated hydroxytoluene (BHT; 0.5 M BHT in acetonitrile) then boiled in a water bath at $100^{\circ} \mathrm{C}$ for 60 min. After boiling, the samples were cool down on ice immediately. The supernatants were measured at $532 \mathrm{~nm}$. The lipid peroxide levels were compared with a standard curve produced from MDA. The results were expressed as nmole/ml.

\section{Homeostatic model assessment of insulin resistance (HOMA-IR)}

HOMA-IR is a method used to quantify beta-cell function and insulin resistance [29]. Subjects were considered as insulin resistant when HOMA $\geq 2.6[30,31]$. HOMA-IR was calculated as:

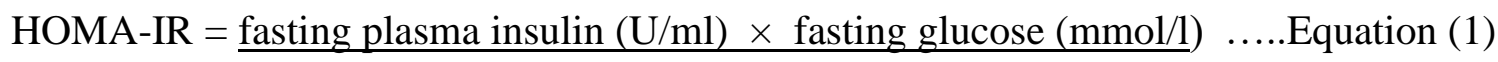

$$
22.5
$$

\section{Statistical analysis}

All data were expressed as means \pm SEM. Statistical significance in body weight, food intake, glucose, insulin, MDA, and hs-CRP in each group and during treatment period was determined using one-way ANOVA and Duncan's multiple range test $(P<0.05)$. Paired sample t-test $(P$ $<0.05)$ also determined the blood glucose of baseline and treatment group at various time.

\section{RESULTS AND DISCUSSION}

\section{Chemical composition of $N K J$}

On a $100 \mathrm{~g}$ dry basis, freeze-dried $N K J$ powder demonstrated $2.25 \pm 0.02 \mathrm{~g}$ moisture, $24.33 \pm 0.11$ $\mathrm{g}$ protein, $51.96 \pm 0.11 \mathrm{~g}$ fat, $8.86 \pm 0.05 \mathrm{~g}$ ash, $1.67 \pm 0.30 \mathrm{~g}$ dietary fiber, and $12.60 \pm 0.01 \mathrm{~g}$ carbohydrate. Iron, zinc, sodium, calcium, magnesium, potassium, and phosphorus were $45.54 \pm 0.74, \quad 16.19 \pm 0.00, \quad 12,762.94 \pm 102.57, \quad 1,494.99 \pm 0.12, \quad 1,063.44 \pm 8.71, \quad 45.58 \pm 0.74$, $2,656.93 \pm 26.78 \mathrm{mg} / \mathrm{kg}$ dry sample respectively.

\section{Effect of NKJ extracts on body weight, food consumption and blood glucose of diabetic rats}

\section{Body weight assessment}

During the experiment, all rats demonstrated no significant difference in body weights among all groups after 3 weeks of feeding with NSS, Metformin and NKJ extracts in diabetic rats (Figure 1). However, Metformin and $200 \mathrm{mg} / \mathrm{kg}$ of $N K J$ extract-treated rats showed a slight weight gain (from $274.13 \pm 10.57$ to $290.75 \pm 16.28$ and from $334.00 \pm 25.17$ to $355.75 \pm 25.34 \mathrm{~g}$, 
respectively) throughout the duration of the experiment. Other groups showed slight decrease in weight. Sindhu and colleagues [32] and Quinn [33] proposed that two main reasons for weight loss during diabetes are lipolysis and gluconeogenesis.

Figure 1. Weight change of Alloxan induced diabetic rats treated with normal saline solution (NSS), Metformin, aqueous extract of $N K J$ at the dose of 200, 1000, and $2000 \mathrm{mg} / \mathrm{kg}$ body weight for 21 days.

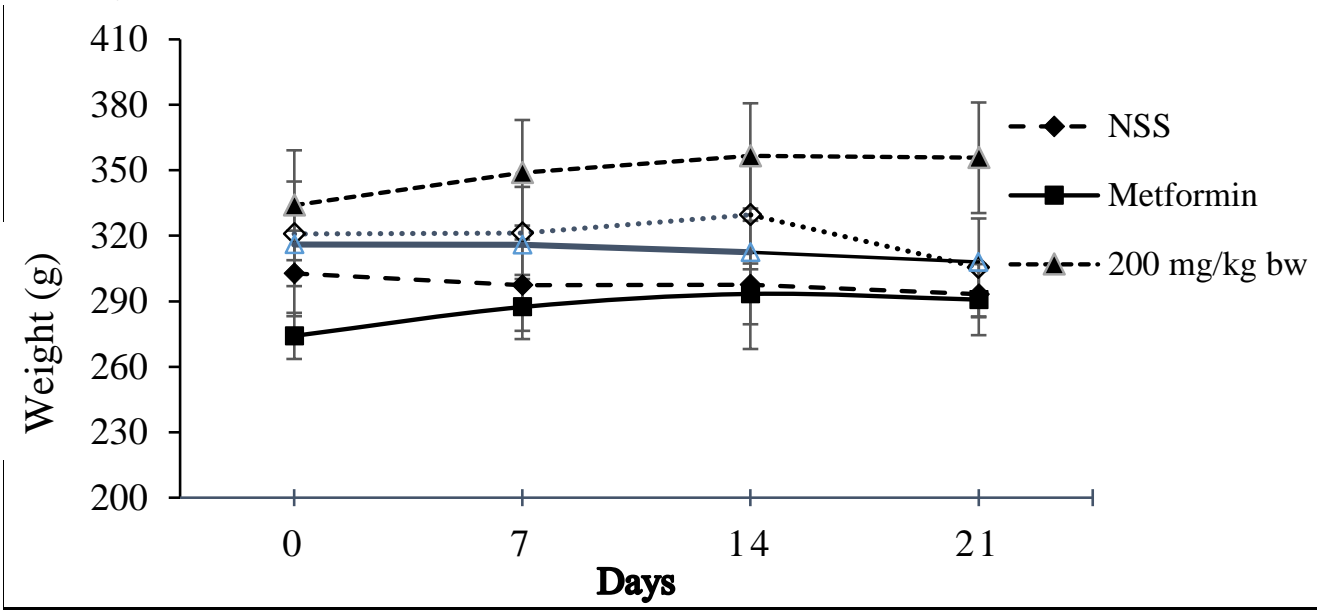

\section{Food consumption}

The effects of various concentrations of $\mathrm{t}$ ] Days vater extract and Metformin on food intake in diabetic rats are observed (Figure 2). Tnere was a considerable increase in the food intake of diabetic rats compared to non-diabetic rats $(20 \mathrm{~g} / \mathrm{rat} / \mathrm{day})$. For diabetic rats, the amount of food intake was not significantly different among all groups.

After 21 days, diabetic controlled (NSS) rats consumed significantly more food than treated groups ( 200 and $2000 \mathrm{mg} / \mathrm{kg}$ food extract). However, there was no significant difference in food consumption between Metformin and $N K J$ extracted groups at the end of the 21-day the experiment at $\mathrm{p}<0.05$. The possible mechanism of Metformin treated group to reduce weight may be an anorectic effect [34].

Figure 2. Amount of food intake in Alloxan-induced diabetic rats through the feeding period.

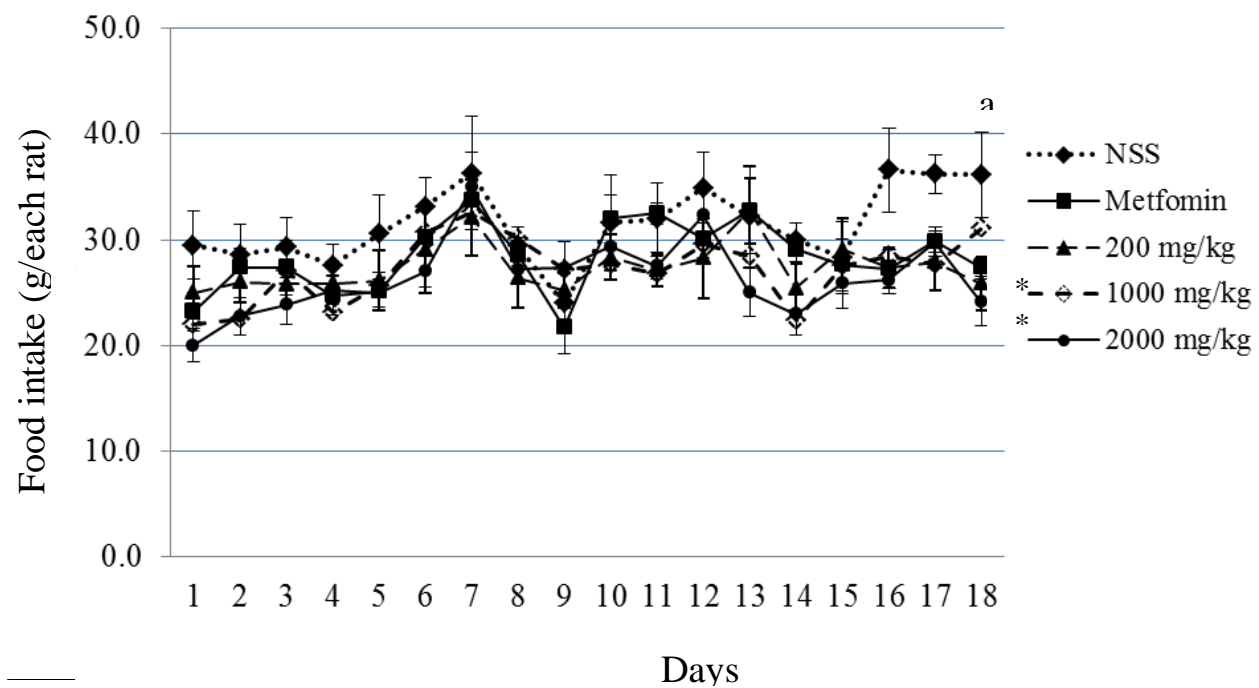




\section{Blood glucose levels}

Male Wistar rats administered for three consecutive days by intraperitoneal injection of Alloxan monohydrate $(100 \mathrm{mg} / \mathrm{kg}$ body weight $)$ demonstrated the progression of diabetes symptoms within 7-days post injection $(\mathrm{p}<0.05)$ and became diabetes as the criteria for fasting blood glucose (FBG) more than $200 \mathrm{mg} / \mathrm{dl}$. The changes of FBG during 21-day of experiment are shown in Figure 3. The common FBG in rats was $104.44 \pm 6.86 \mathrm{mg} / \mathrm{dl}$ and for diabetic rats was $337.45 \pm 11.80 \mathrm{mg} / \mathrm{dl}$.

Figure 3. Fasting blood glucose $(\mathrm{mg} / \mathrm{dl})$ level in normal rats and Alloxan-induced diabetic rats at baseline and after being treated with $N K J$ water extract for 7,14 , and 21 days.

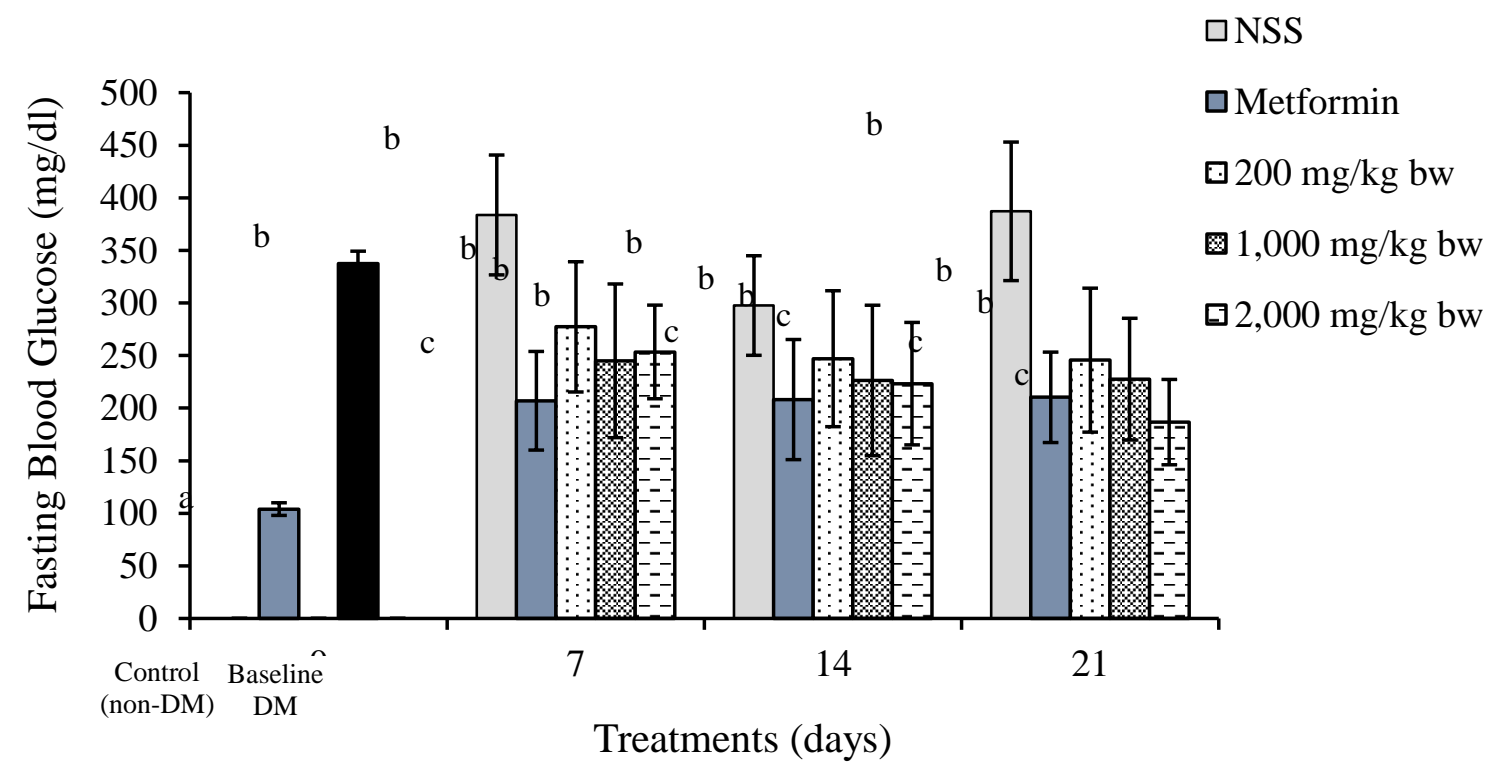

Values are given as mean $\pm \mathrm{SE}(\mathrm{n}=7)$. ${ }^{\mathrm{a}, \mathrm{b}, \mathrm{c}}$ Significant difference compare with baseline diabetic rats $(\mathrm{DM})$ at $p<0.05$.

Metformin and $N K J$ water extract supplement group decreased blood glucose levels in diabetic rats and increased in the NSS treated group. At day 7, 14, and 21 of the experiment, blood glucose levels of Metformin ( $200 \mathrm{mg} / \mathrm{kg}$ body weight) treated group were significantly lower compared to the initial induction period ( $\mathrm{p}<0.05$ ). The results of $N K J$ water extract (all three doses) exhibited decreased FBG in a dose dependent manner especially for the second and third week of the treatments (day 14,21) in diabetic rats. A significant decrease in blood glucose level was found at day 14 and day 21 of treatment with crude extract $(2000 \mathrm{mg} / \mathrm{kg})$. This study demonstrated that diabetic rats consuming the $N K J$ water extract could lower their FBG compared to the negative control (NSS). Compared to Metformin treated rats, a standard drug commercially used for lowering blood glucose in diabetic patients, there was no significant difference in FBG.

Inflammation is related to insulin resistance [35]. Insulin treated diabetics, when provided with high dose Aspirin (an anti-inflammatory drug), would no longer be required to receive 
daily insulin injection. FBG concentration was almost normal when treated with Aspirin alone [35]. The NKJ water extract similarly demonstrated lower FBG and insulin resistance. This may also be related to the highest anti-inflammatory activity found in the NO inhibition experiment.

Inflammatory response is a complex phenomenon involving numerous mediators, a number of which are potentially affected by polyphenols in culinary herbs and spices [36]. There are two possible cellular pathways including arachidonic dependent pathways and arachidonic independent pathways [37]. Arachidonic dependent pathways occur via the action of cyclo-oxygenase (COX) enzymes [38]. Apigenin from parsley has been shown to be related to this mechanism that might stop the inflammation process [39]. Arachidonic independent pathways can involve phenolic compound. Peroxisome proliferator activated receptors (PPARs), NOS, and NF- $\mathrm{KB}$ are involved in regulating the expression of pro-inflammatory cytokines, including IL-8 [37].

A polyphenol that can inhibit the pro-inflammatory NF- $\kappa B$ pathway is curcumin, a main bioactive compound in turmeric [40]. Once NF- $\mathrm{B}$ is inhibited, an improvement in insulin sensitivity would be evident [41], suggesting that the NF- $\kappa B$ pathway plays an important role in inflammation-associated insulin resistance [42].

Our finding suggests that bioactive compounds such as curcumin from turmeric (used in $N K J$ ) can similarly inhibit the inflammation process in arachidonic independent pathway, which in turn reduces insulin resistance in diabetic rats.

Chemical and Pharmacological studies have reported that several bioactive compounds could manage DM and control DM complications [43]. Many ingredients used in Thai foods contain anti-oxidant and anti-inflammatory substances that can relieve the diabetic condition [44]. In our study, $N K J$ water extract significantly reduced the FBG level in diabetic rats for several reasons. For example, bioactive peptides and metabolite from fish used in $N K J$ demonstrated the ameliorating effect in diabetic rats. Mirmiran and colleagues [45] and Boukortt and colleagues [46] reported a reduction in insulin resistance from food made with fish and sea food together with anti-inflammation and reduced oxidative stress. However, the ameliorating effect of diabetic rats may be the combined effect from many bioactive ingredients in $N K J$ extracts.

\section{Plasma insulin levels}

A plasma insulin level was determined in Alloxan-induced diabetic rats. At the beginning, plasma insulin level in the normal control (non-DM) and 7-days post induction of baseline (DM) group of diabetic rats were measured. The plasma insulin level in the DM group was significantly higher than the control (non-DM) group. Three weeks of daily oral treatment of Metformin and $N K J$ water extract at 200,1000, and $2000 \mathrm{mg} / \mathrm{kg}$ body weight demonstrated a significant decrease of insulin secretion compared with the baseline (DM) group $(p<0.05$, Figure 4A) but no significant difference with the control (Non-DM) group. 
Figure 4. Insulin $(\mu \mathrm{IU} / \mathrm{ml})(\mathrm{A})$, hs-CRP $(\mathrm{mg} / \mathrm{l})(\mathrm{B})$ and MDA $(\mathrm{nmol} / \mathrm{ml})(\mathrm{C})$ concentrations level in control (non-diabetic rats), baseline (diabetic

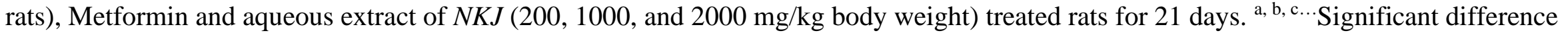
compared with the control (non-DM rats) at $p<0.05$.

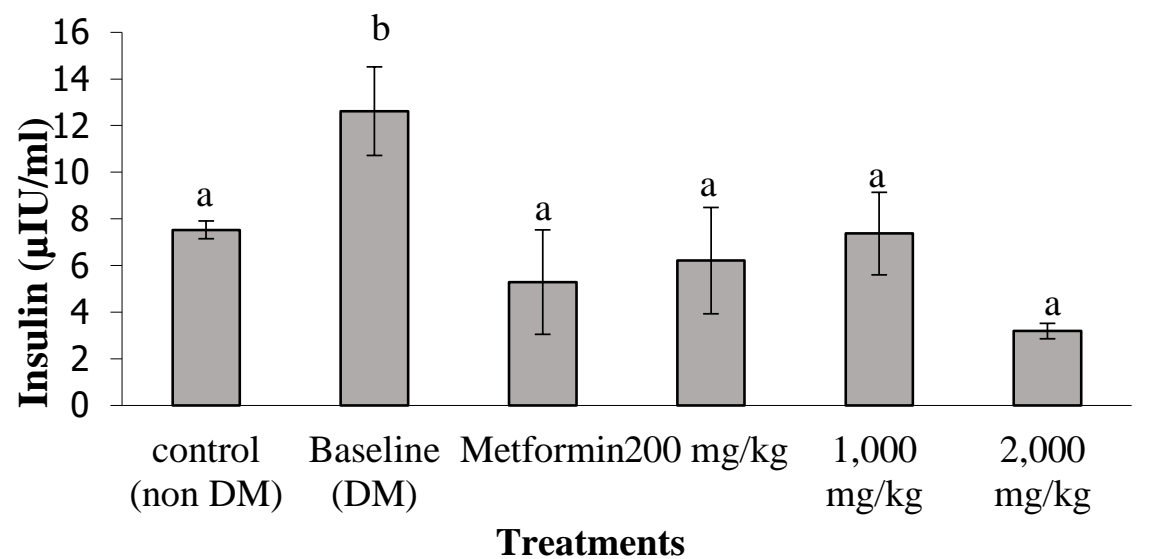

Treatments
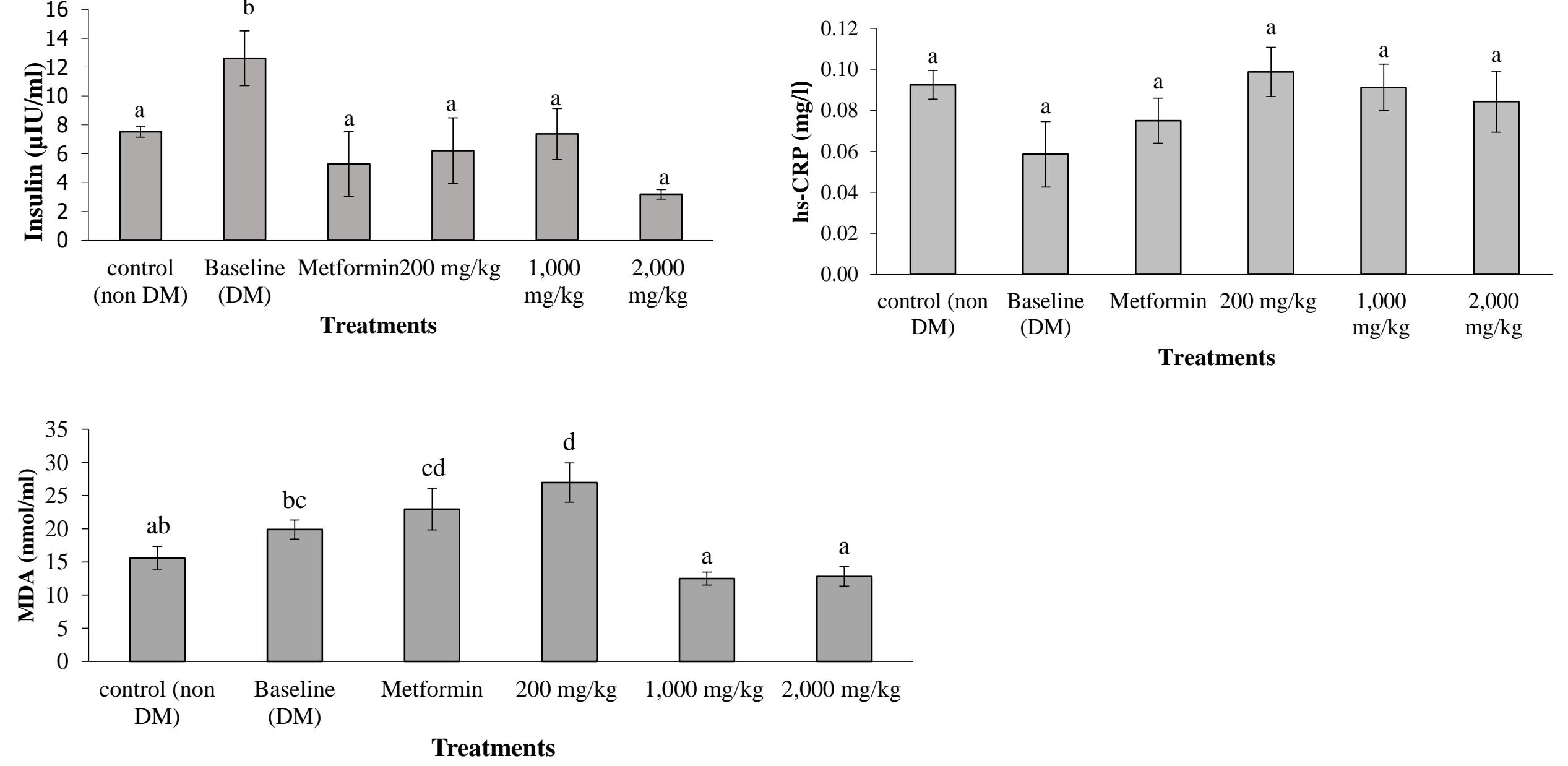
When Alloxan was injected in diabetic rats, induced oxidative stress in islets of Langerhans of pancreas resulted in significantly high insulin secretion from beta-cells compared to the normal control group. The cytotoxic effects of Alloxan in pancreatic beta-cells might stimulate the secretion of insulin in diabetic rats. In contrast, low levels of insulin in Metformin and $N K J$ water extract treated groups reveals a decrease in FBG compared with the DM group.

Metformin is a biguanide antihyperglycemic agent widely used in management of type 2 diabetes. Metformin reduces blood glucose by decreasing hepatic glucose production, decreasing intestinal absorption of glucose, improving insulin sensitivity by increasing peripheral glucose uptake and utilization [34]. This drug was not completely absorbed (20-30\% of the oral dose), possibly due to the active absorption process. Oral bioavailability of the drug is approximately 33-55\% [47]. Therefore, oral administration of Metformin reduces hepatic blood glucose and indirectly controls insulin secretion.

\section{High-sensitive C - reactive protein (hs-CRP) levels}

Diabetes mellitus characterized by hyperinsulinemia is believed to play a major role in cellular inflammation [48]. Several mediators of inflammation have been reported in diabetic patients. One of the main predictive inflammation mediators for progression of diabetes, hs-CRP, was measured. The result demonstrated no significant difference between treatment and control groups (Figure 4B). These high levels of hs-CRPs may induce the activation of innate immune system in diabetic patients due to several factors such as over nutrition and infection.

However, these inflammatory mediators do not clearly reveal the magnitude of inflammation in different peripheral tissues. Moreover, the circulating levels of these mediators vary from individual to individual and tissue to tissue [4]. The short duration of the experiments limited the ability for proving the effect of our intervention on the hs-CRP levels. For example, for Lycopene, 12-week exposure would be necessary to demonstrate an effect, as shown in the case of lycopene supplement in young overweight adults leading to a reduction of hs-CRP [49].

\section{Malonylaldehyde (MDA)}

The effects of $N K J$ water extracts on lipid peroxidation were studied as MDA level at the $3^{\text {rd }}$ week of Alloxan-induced diabetic rats, as shown in Figure 4C. Diabetic rats demonstrated a trend to have higher lipid peroxidation compared to normal rats. With Metformin and small dose of $N K J(200 \mathrm{mg} / \mathrm{kg})$, MDA levels were higher than normal control rats. Higher dose of $N K J$ extracts (1000 and $2000 \mathrm{mg} / \mathrm{kg}$ ) could reduce lipid oxidation to a normal level. Significantly, MDA was significantly higher in rats receiving small dose of $N K J$. With higher weight of this group, despite similar intake and FBG of other diabetic groups it is possible that the metabolism of these rats are lower than other diabetic rats. However, this observation needs to be explored further. From these results, the high concentration of $N K J$ water extract can potentially reduce lipid oxidation, as indicated by the decreased amount of MDA.

\section{Homeostatic model assessment of insulin resistance (HOMA-IR)}

The concentrations of FBG and plasma insulin were measured. HOMA-IR was calculated in diabetic Wistar rats. Figure 5 demonstrated the HOMA-IR in normal rats and Alloxan-induced 
diabetic rats. There was no significant difference between normal, Metformin, and $N K J$ water extract treated rats. The diabetic rats demonstrated significantly higher resistance compared to other groups. The $N K J$ extract was concluded to significantly reduce the insulin resistance compared to the diabetic control group. No significant difference in HOMA-IR levels was observed between $N K J$ treated group and Metformin treated groups.

Figure 5. Homeostatic model assessment of insulin resistance (HOMA-IR) in alloxan induced diabetic rats. ${ }^{\mathrm{a}, \mathrm{b}}$ Significant difference compared with the control (non-diabetic rats) at $p<$ 0.05 .

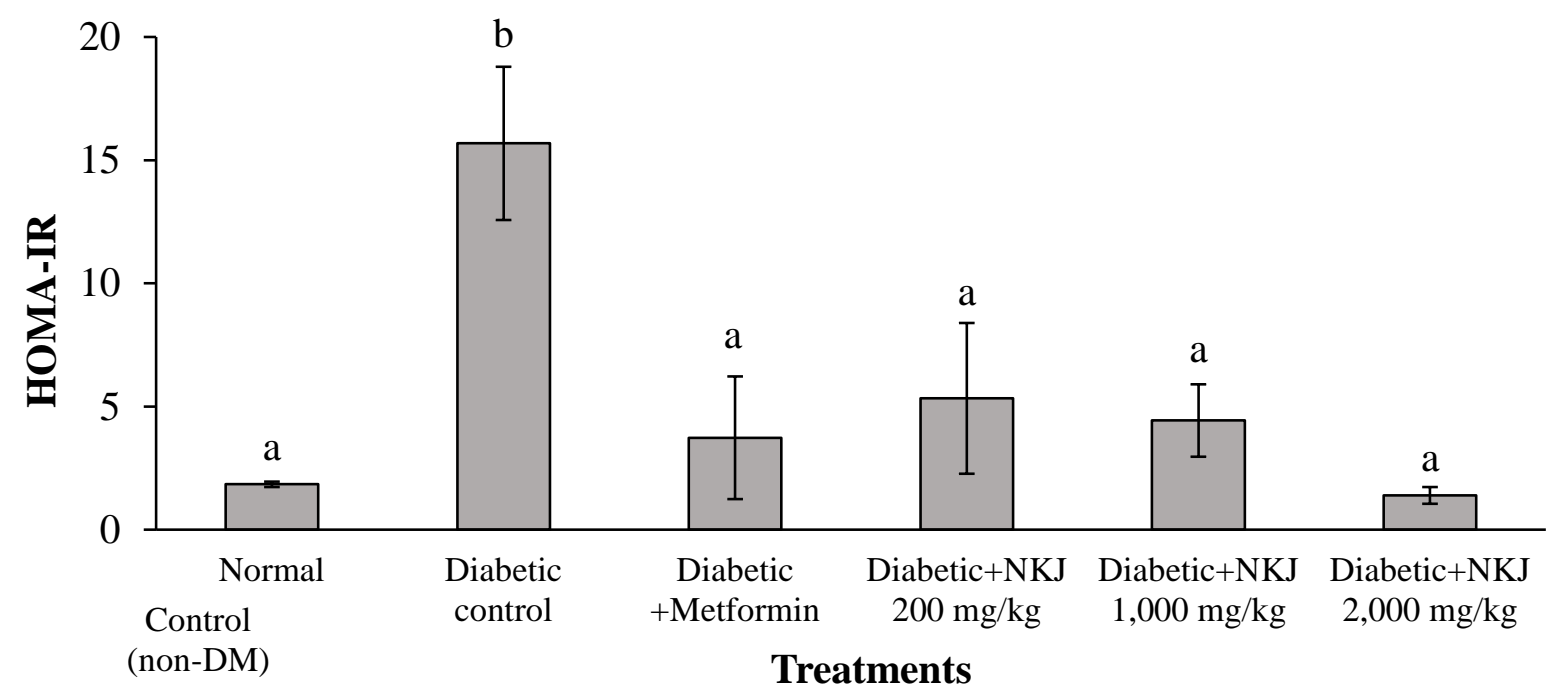

\section{CONCLUSION}

The present study has demonstrated that aqueous of $N K J$ (defatted) exerted anti-oxidant and anti-inflammatory activities in in vitro model. The crude water extracts of $N K J$ contained the highest amount of total phenolic exhibited relatively lower anti-oxidant activity but demonstrated a high potential effect on inflammatory activity.

FBG levels in Alloxan-induced diabetic rats model by intraperitoneal injection are as follows. After treatment with aqueous extracts of $N K J$ for 3 weeks, the results demonstrated that FBG levels decreased in Metformin, and $N K J$-extract treated rats while the FBG level in NSS group increased. In DM groups where rats were fed with $N K J$ extract at 3 doses (200, 1000, and $2000 \mathrm{mg} / \mathrm{kg} \mathrm{BW}$ ), a decrease in FBG in a dose dependent manner was observed, especially during 14-21 days of the treatment. NKJ contains several bioactive water soluble ingredients, such as piperine from black pepper (Piper nigrum Linn), HCA from Garcenia Combogia, and bioactive peptide from fish.

The ameliorating effects of DM rats would be the combined effects from these bioactive ingredients. There was also no significant difference in FBG compared to Metformin treated rats, a standard drug commercial use for lowering blood glucose in diabetic patients. This study indicated that feeding water extract of $N K J$ to diabetic rats could lower the FBG when compared with the negative control (normal saline) as well as adjusting the oxidative stress (MDA) lowered to normal level range. In contrast, the Metformin treated group remained 
elevated in oxidative stress throughout the study. Thus, treatment with $N K J$ extracts not only improves diabetic biomarkers but also re-adjusts the level of oxidative stress to normal level within the time period study. This is a key promising characteristic for correcting the metabolic syndrome condition.

List of Abbreviations: Namya Kanom Jeen (NKJ), Fasting Blood Glucose (FBG), diabetes mellitus (DM), normal saline solution (NSS), reactive oxygen species (ROS), reactive nitrogen species (RNS), nitric oxide (NO), inducible nitric oxide synthase (iNOS), high sensitivity Creactive protein (hs-CRP), Total phenolic content (TPC), Homeostatic model assessment of insulin resistance (HOMA-IR), Malondialdehyde (MDA)

Author Contributions: Pavinee Chinachoti, Rattana Leelawattana and Preeya Dat-arun designed the research. Pavinee Chinachoti conducted the research and wrote the manuscript. All authors read and approved the final version of the manuscript.

Competing Interests: There are no conflicts of interest to declare.

Acknowledgements and Funding: This work was supported by the Higher Education Research Promotion and National Research University Project of Thailand, Office of the Higher Education Commission. We thank the staff of the Southern Laboratory Animal Facility, Faculty of Science, and Prince of Songkla University for help.

\section{REFERENCES}

1. Chaturvedi N: The burden of diabetes and its complications: trends and implications for intervention: Diabetes Res Clin Pract 2007, 76:3-12.

2. Wilcox G: Insulin and insulin resistance: Clin Biochem Rev 2005, 26:19-39.

3. Evans JL, Maddux BA, Goldfine ID: The molecular basis for oxidative stressinduced insulin resistance: Antioxid Redox Signal 2005, 7:1040-1052.

4. Donath MY, Shoelson SE: Type 2 diabetes as an inflammatory disease: Nat Rev Immunol 2011, 11:98-107.

5. Evans JL, Goldfine ID, Maddux BA, Grodsky GM: Oxidative stress and stressactivated signaling pathways: A unifying hypothesis of type 2 diabetes: Endocr Rev 2002, 23:599-622.

6. Fiorentino TV, Prioletta A, Zuo P, Folli F: Hyperglycemia-induced oxidative stress and its role in diabetes mellitus related cardiovascular diseases: Curr Pharm Des 2013, 19:5695-5703.

7. Maritim AC, Sanders RA, Watlins JB: Diabetes, oxidative, and anti-oxidants: J Biochem Mol Toxicol 2003, 173:24-38.

8. Robertson RP, Harmon J, Tran PO, Tanaka Y, Takahashi H: Glucose toxicity in betacells: type 2 diabetes, good radicals gone bad, and the glutathione connection: Diabetes 2003, 52:581-587. 
9. Lorenzi M: The polyol pathway as a mechanism for diabetic retinopathy: attractive, elusive, and resilient: Exp Diabetes Res 2007, DOI: 10.1155/2007/61038.

10. Poyton RO, Castello PR, Ball KA, Woo DK, Pan N: Mitochondria and hypoxic signaling. Ann N Y Acad Sci 2009, 1177:48-56.

11. Cianchi F, Cortesini C, Fantappie O, Messerini L, Sardi I, Lasagna N, Perna F, et al.: Cyclooxygenase- 2 activation mediates the proangiogenic effect of nitric oxide in colorectal cancer: Clin Cancer Res 2004, 10:2694-2704.

12. Bi X, Lim J, Henry CJ: Spices in the management of diabetes mellitus. Food Chem 2016, 217:281-293.

13. Hollander P: Anti-diabetes and anti-obesity medications: effects on weight in people with diabetes. Diabetes Spectr 2007, 20: 159-165.

14. Perera HK, Handuwalage CS: Analysis of glycation induced protein cross-linking inhibitory effects of some antidiabetic plants and spices: BMC Complement Altern Med. 2015: 15:1-9.

15. Kim Y, Keogh JB, Clifton PM: Polyphenols and glycemic control: Nutrients 2016, 8(1):17. doi:10.3390/nu8010017.

16. Choudhury H, Pandey M, Hua CK, Mun CS, Jing JK, Kong L, Ern LY, et al.: An update on natural compounds in the remedy of diabetes mellitus: A systematic review. J Tradit Complement Med 2017, 1-16.

17. Khan A, Safdar M, Ali Khan MM, Khattak KN, Anderson RA: Cinnamon improves glucose and lipids of people with type 2 diabetes. Diabetes Care 2003, 26:32153218.

18. Krishnaswamy K: Traditional Indian spices and their health significance. Asia Pac J Clin Nutr 2008, 17:265-268.

19. Arts IC, Hollman PC: Polyphenols and disease risk in epidemiologic studies. Am. J. Clinical. Nutr 2005, 81:317-325.

20. Charoenkiatkul S, Muangnoi1 C, Chingsuwanrote P, Praengamthanachoti P, Tuntipopipat S, Svasti S: Stir-fry chicken with green curry suppresses inflammatory gene expression by lipopolysaccharide-induced murine macrophages: Food Nutr Sci 2011, 2:770-779.

21. Prangthip P, Charoenkiatkul S, Kettawan A, Okuno M, Okamoto T: Thai red curry paste lowers glucose, oxidative stress and insulin levels in type II diabetic rats: Int Food_Res_ J 2012, 2:623-627.

22. Dat-arun P: Anti-oxidative and anti-inflammatory properties of traditional Southern Thai food extracts and their influences on biomarkers of glucose metabolism: Ph.D. Dissertation, Department of Functional Food and Nutrition, Prince of Songkla University, Thailand 2016: 191p. 
23. Charoenkiatkul S, Dissayabutr W, Boonpraderm A, Titatan Y, Ruamruk M: Development of Thai set menu: Research report submitted to Thailand National Research Council 2005, September.

24. AOAC. Official methods of analysis (17th ed.) Gaithersberg, Maryland: Association of Official Analytical Chemists; 2000.

25. Saidu UW, Ladan MJ, Bilbis LS, Ibrahim ND: Anti-oxidant status and lipid profile of diabetic rats treated with anti-oxidant rich locally prepared nutraceutical: Int $\mathbf{J}$ Disease Disorder 2013, 1:033-038.

26. Akinola O, Gabriel M, Suleiman AA, Olorunsogbon F: Treatment of alloxan-induced diabetic rats with metformin or glitazones is associated with amelioration of hyperglycemia and neuroprotection: Open Diabetes J 2012, 5:8-12.

27. Kesari AN, Gupta RK, Singh SK, Diwakar S, Watal G: Hypoglycaemic and antihyperglycaemic activity of Aegle marmelos seed extract in normal and diabetic rats: J Ethnopharmacol 2006, 107:374-379.

28. Ohkawa H, Ohishi N, Yagi K: Assay for lipid peroxides in animal tissues by thiobarbituric acid reaction: Anal Biochem 1979, 95:351-358.

29. Matthews DR, Hosker JP, Rudenski AS, Naylor BA, Treacher DF, Turner RC: Homeostasis model assessment: insulin resistance and beta-cell function from fasting plasma glucose and insulin concentrations in man: Diabetologia 1985, 28: 412-419.

30. McAuley KA, Williams SM, Mann JI, Walker RJ, Ledwis-Barned NJ, Temple LA, Duncan AS: Diagnosing insulin resistance in the general population: Diabetes Care 2001, 24:460-464.

31. DeFronzo RA: Insulin sensitivity indices obtained from oral glucose tolerance testing: comparison with the euglycaemic clamp: Diabetes Care 1999, 22:1462-1470.

32. Sindhu RK, Koo JR, Roberts CK, Vaziri ND: Dysregulation of hepatic superoxide dismutase, catalase and glutathione peroxidase in diabetes: response to insulin and anti-oxidant therapy: Clin Exp Hypertension 2004, 26:43-53.

33. Quinn L: Mechanism in the development of type 2 diabetes mellitus: J Cardiovas Nursing 2002, 16:1-16.

34. Gaal LV, Scheen A: Weight management in Type 2 Diabetes: current and emerging approaches to treatment: Diabetes care 2015, 38:1161-1172.

35. Reid J, MacDougal AI, Andrews MM: Aspirin and diabetes mellitus: Br Med J 1957, 2: 1071-1074.

36. Yoon JH, Baek SJ: Molecular targets of dietary polyphenols with anti-inflammatory properties: Yonsei Med J 2005, 46: 585-596.

37. Opara EI, Chohan M: Culinary herbs and spices: their bioactive properties, the contribution of polyphenols and the challenges in deducing their true health benefits: Int J Mol Sci 2014, 15: 19183-19202. 
38. Kim SS, Oh O, Min H, Park E, Kim Y, Park H, Han YN, et al.: Eugenol suppresses cyclooxygenase-2 expression in liposaccharide-stimulated mouse macrophage RAW264.7 cells: Life Sci 2003, 73: 337-348.

39. Pan MH, Lai CS, Ho CT: Anti-inflammatory activity of natural dietary flavonoids: Food Func 2010, 1: 15-31.

40. Dhandapani KM, Mahesh VB, Brann DW: Curcumin suppresses growth and chemoresistance of human glioblastoma cells via AP-1 and NF- $\mathrm{BB}$ transcription factors: J Neurochem 2007, 102: 522-538.

41. Chen L, Chen R, Wang H, Liang F: Mechanisms linking inflammation to insulin resistance: Int J Endocrinol 2015, DOI: 10.1155/2015/508409.

42. Yekollu SK, Thomas R, Sullivan BO: Targeting curcusomes to inflammatory dendritic cells inhibits NF- $\kappa \mathrm{B}$ and improves insulin resistance in obese mice: Diabetes 2011, 60: 2928-2938.

43. Perera PK, Li Y: Functional herbal food ingredients used in type 2 diabetes mellitus: Pharmacogn Rev 2012, 6:37-45.

44. Tuntipopipat S, Muangnoi C, Chingsuwanrote P, Parengam M, Chantravisut P, Charoenkiatkul S, Svasti S: Anti-inflammatory activities of red curry paste extract on lipopolysacchaide-activated murine macrophage cell line: Nutrition 2011, 27: 479-487.

45. Mirmiran P, Bahadoran Z, Azizi F: Functional foods-based diet as a novel dietary approach for management of type 2 diabetes and its complications: a review: World J Diabetes 2014, 5:267-281.

46. Boukortt FO, Girard A, Prost JL, Ait-Yahia D, Bouchenak M, Belleville J: Fish protein improves the total anti-oxidant status of streptozotocin-induced diabetes in spontaneously hypertensive rat: Med Sci Monit 2004, 10:397-404.

47. Choi YH, Lee MG, Lee I: Effects of diabetes mellitus induced by alloxan on the pharmacokinetics of metformin in rats: restoration of pharmacokinetic parameters to the control state by insulin treatment: J Pharm Pharmaceut Sci 2008, 11:88-103.

48. Ruge T, Lockton JA, Renstrom F, Lystig T, Sukonina V, Svensson MK, Eriksson JW: Acute hyperinsulinemia raises plasma interleukin- 6 in both nondiabetic and type 2 diabetes mellitus subjects and this effect is inversely associated with body mass index: Metab Clin Exp 2009, 58:860-866.

49. Thies F, Masson LF, Rudd A, Vaughan N, Tsang C, Brittenden J, Simpson WG, et al.: Effect of a tomato-rich diet on markers of cardiovascular disease risk in moderately overweight, disease-free, middle-aged adults: a randomized controlled trial: Am J Clin Nutr 2012, 95:1013-1022. 